\title{
Susceptibility of different leaf stages of Hevea to Corynespora cassiicola
}

\author{
T H P S Fernando*, C K Jayasinghe*, R L C Wijesundera** \\ and D Siriwardena* \\ * Rubber Research Institute of Sri Lanka \\ ** Department of Plant Science, University of Colombo, Sri Lanka
}

Received 23 June 2010: Accepted 27 January 2011

\begin{abstract}
Corynespora leaf fall disease caused by Corynespora cassiicola is considered one of the most destructive foliar diseases of rubber. The pathogen affects the leaves causing leaf fall throughout the year. According to the results of this study the young leaf stages, copper brown and late copper brown, were the most susceptible to CLFD. With maturity, the lesion sizes reduced and it was not possible to artificially inoculate mature leaves from any clone. The observations were confirmed by results from the field experiments. The results of this investigation suggests that the fungicide spray rounds could be minimized if spraying programme is scheduled targeting the refoliation period.
\end{abstract}

Key words: Corynespora cassiicola, Hevea brasiliensis, leaf stages

\section{Introduction}

Corynespora leaf fall disease (CLFD), a disease of recent origin caused by the fungus Corynespora cassiicola is now a serious threat to the natural rubber production in almost all rubber growing countries in the Asian \& African continents (Newsam, 1961; Kajornchaiakul, 1987; Liyanage et al., 1986; Soepena, 1985 Ramakrishnan \& Pillay, 1961; Dung and Hoan, 1999; Jinji et al., 2007; Pongthep, 1987). During the initial period, $C$. cassiicola was considered as a weak pathogen of Hevea rubber and the disease was limited to deficient bud wood nurseries and seeding nursery plants. However, during the latter part of the $20^{\text {th }}$ century, the disease spread to many rubber growing countries causing extensive damage to rubber plantations.

CLFD was first detected in Sri Lanka during the year 1985 (Liyanage et al., 1986) and reached epidemic proportions. The first epidemic devastated the clone RRIC 103, one of the prestigious clones bred by Sri Lankan scientists in the $20^{\text {th }}$ century. The total area affected was around 4500 ha representing nearly $3 \%$ of the cultivated rubber land at that time. Consequently in 1995, a second 
epidemic was experienced and the outstanding clone RRIC 110, succumbed to CLFD. During the recent past more than a dozen of potential high yielding clones were withdrawn from experimental sites as they were found to be highly susceptible to CLFD (Jayasinghe et al., 1999). Similarly, other rubber growing countries are also facing this dilemma as their high yielding clones such as GT 1, RRIM 600 and RR11 105 has become susceptible to the disease (Jacob, 2003; Jayasinghe, 2000).

It is well documented that rubber clones once tolerant to the disease had later become susceptible. Therefore, it is critically important to improve the available strategies to manage and control the disease. Unlike other common leaf diseases of rubber, the management of the disease on mature trees is more difficult and costly as continuous fungicide sprays are required for protection. In this study, the susceptibility of different leaf stages to CLFD was investigated as an understanding of the influence of different leaf stages on the development of the disease is essential in the formulation of a more cost-effective method of control.

\section{Materials and Methods \\ The organism}

Fifteen Corynespora cassiicola isolates were obtained from different clones of Hevea brasiliensis. All isolates were purified and single spore cultures were raised on potato dextrose agar (PDA) (Difco) at RT $\left(28 \pm 2^{\circ} \mathrm{C}\right)$. Based on cultural, reproductive characteristics and pathogencity isolate $\mathrm{E}$, a high sporulator was used throughout the investigation. Cultures were maintained on PDA at room temperature $\left(28 \pm 2^{\circ} \mathrm{C}\right)$ after establishing their pathogenicity on rubber plants.

\section{Preparation of the conidial suspension}

A suspension of conidia was prepared using 10-day old cultures on PDA by flooding the plate with sdw. The conidia were harvested by scraping the colonies with a paint brush. The resulting suspension was filtered through a single layer of gauze to remove mycelial fragments and the conidial concentration of the resulting suspension was estimated using a haemocytometer. The concentration was adjusted to $5 \times 10^{4}$ conidia/ml using sdw.

\section{Plant materials}

Five leaf stages (listed below) of a CLFD resistant clone (RRIC 121) and a CLFD susceptible clone (RRISL 201) were used for the experiments under laboratory conditions. Evaluations in bud wood nurseries was done using the clone, RRIC 110 and under field conditions RRISL 202 was used.

\section{The leaf stages}

$\mathrm{C}_{1} \quad$ - Copper brown (very immature)

$\mathrm{C}_{2}$ - Late copper brown stage with apple green appearance

A - Apple green

SM - Semi - mature

M - Mature 


\section{Leaf inoculation}

Detached leaf technique adopted by Brown \& Soepena (1994) was slightly modified and used. Six replicate leaves from each maturity stage were inoculated with $0.02 \mathrm{ml}$ of the conidial suspension $\left(5 \times 10^{4}\right.$ conidia/ml $)$ on either side of the mid rib. The inoculated leaves were incubated at RT under $100 \%$ RH.

\section{Assessment of pathogenicity \\ Observations of lesion production on inoculated leaves were made daily for five days after inoculation and the lesions were grouped into one of the five categories listed below based on the size of the lesion. Lesion groupings were; Group 1 - no reaction; Group 11 - pin point sized lesions; Group 111 - pin head sized lesions; Group 1V - moderately extended lesions with slight growth of mycelium; Group V - more extended lesions with profusely grown mycelium. Each test was repeated three times.}

\section{Testing under field conditions}

Twenty twigs of the clone RRISL 202, at RRISL substation, Rathnapura were tagged. The fungicides, carbendazim at a rate of $1.0 \mathrm{~g} / \mathrm{litre}$ and mancozeb $3.0 \mathrm{~g} / \mathrm{litre}$ were alternatively sprayed at $3-4 d$ intervals using a hand sprayer to protect the twigs against CLFD. Chemical application was initiated from the start of bud-burst till the leaves matured.

\section{Testing under bud wood nursery conditions}

Twenty twigs of the clone RRISL 110 at RRISL substation, Rathnapura were tagged. The fungicides; carbendazim at a rate of $1.0 \mathrm{~g} /$ litre and mancozeb $3.0 \mathrm{~g} /$ litre were alternatively sprayed at $3-4 \mathrm{~d}$ intervals using a hand sprayer till the leaves matured. Twenty twigs each from the bud wood nursery plants and field plants from the same clones were tagged and kept without fungicide application as the control.

\section{Disease assessment}

In both experiments described above the tagged twigs were observed after 6 months for the appearance of CLFD lesions. The number of leaves with CLFD spots was given as a percentage. Each experiment was repeated twice in 2008 \& 2009.

\section{Results and Discussion \\ Laboratory experiments}

The development of the disease of artificially inoculated detached leaves under laboratory conditions was similar in both CLFD resistant clones and susceptible clones. According to the results, copper brown or late copper brown stages were the most susceptible. With maturity the sizes of lesions decreased. The artificial inoculation of mature leaves did not produce the disease in any clone (Table 1).

\section{Field and nursery experiments}

The percentages of infected leaves under field and nursery conditions are given in Table 2. 
Table 1. Effect of leaf stage on the CLFD infection - in vitro

\begin{tabular}{|c|c|c|c|c|c|c|c|c|c|c|}
\hline \multirow{3}{*}{$\begin{array}{l}\text { Stage of } \\
\text { the leaf }\end{array}$} & \multicolumn{10}{|c|}{ Size of the lesion produced* } \\
\hline & \multicolumn{2}{|c|}{ Day 1} & \multicolumn{2}{|c|}{ Day 2} & \multicolumn{2}{|c|}{ Day 3} & \multicolumn{2}{|c|}{ Day 4} & \multicolumn{2}{|c|}{ Day 5} \\
\hline & R 121 & R 201 & R 121 & R 201 & R 121 & R 201 & R 121 & R 201 & R 121 & R 201 \\
\hline $\mathrm{C} 1$ & II & II & III & III & III & III & IV & IV & $\mathrm{V}$ & $\mathrm{V}$ \\
\hline $\mathrm{C} 2$ & II & II & II & III & III & IV & IV & $\mathrm{V}$ & $\mathrm{V}$ & $\mathrm{V}$ \\
\hline A & II & II & II & II & III & III & IV & IV & $\mathrm{V}$ & $\mathrm{V}$ \\
\hline SM & I & I & II & II & II & II & III & III & III & III \\
\hline M & I & I & I & I & I & I & I & I & I & I \\
\hline
\end{tabular}

Leaf stages: C1 - Copper brown - very immature, C 2 -Late copper brown stage with apple green appearance, $\mathrm{A}$ - Apple green, $\mathrm{SM}$ - Semi mature, $\mathrm{M}$ - Mature,

* I- No symptom, II - pin-point size lesions, III- pin head size lesions, IV- discoloration extended with slight growth of mycelium, V-extended lesions with profuse mycelial growth.

Table 2. The percentage CLFD infected leaves from the twigs under nursery \& field conditions

\begin{tabular}{|c|c|c|c|c|}
\hline \multirow{3}{*}{$\begin{array}{l}\text { No of } \\
\text { Twigs }\end{array}$} & \multicolumn{4}{|c|}{$\%$ Infected leaves } \\
\hline & \multicolumn{2}{|c|}{ Bud wood nursery plants (RRIC 110) } & \multicolumn{2}{|c|}{ Field plants (RRISL 202) } \\
\hline & Treated plants & Control & Treated plants & Control \\
\hline $\mathrm{T} 1$ & 7 & 100 & 6.23 & 66.67 \\
\hline $\mathrm{T} 2$ & 36 & 100 & 9.17 & 59.0 \\
\hline $\mathrm{T} 3$ & 10.1 & 100 & 3.33 & 51.67 \\
\hline $\mathrm{T} 4$ & 8.5 & 95.7 & 1.33 & 83.67 \\
\hline $\mathrm{T} 5$ & 52 & 100 & 1.33 & 71.67 \\
\hline T6 & 43 & 90 & 5.73 & 75 \\
\hline $\mathrm{T} 7$ & 7 & 73.4 & 1.43 & 67.67 \\
\hline $\mathrm{T} 8$ & 15.1 & 85 & 5.93 & 61.67 \\
\hline T9 & 15 & 90 & 0 & 73.67 \\
\hline $\mathrm{T} 10$ & 12 & 100 & 4.67 & 71.67 \\
\hline $\mathrm{T} 11$ & 14 & 85.7 & 0 & 86 \\
\hline $\mathrm{T} 12$ & 4.6 & 90.5 & 0 & 65.33 \\
\hline T13 & 65.5 & 78.2 & 4.27 & 76.67 \\
\hline $\mathrm{T} 14$ & 55.0 & 95.5 & 9.47 & 64.0 \\
\hline $\mathrm{T} 15$ & 30.2 & 92.8 & 4.0 & 81.67 \\
\hline T16 & 38.4 & 90.2 & 1.9 & 71.33 \\
\hline $\mathrm{T} 17$ & 24.2 & 82.5 & 0 & 76.67 \\
\hline T18 & 7.2 & 95 & 4.27 & 77.67 \\
\hline T19 & 8.9 & 92 & 0 & 78.33 \\
\hline $\mathrm{T} 20$ & 7.2 & 82.3 & 2.3 & 75.66 \\
\hline
\end{tabular}


Corynespora cassiicola prefers young leaves and with maturity the sizes of the lesions or the amount of disease reduced. The artificial inoculation of mature leaves under laboratory conditions was not possible (Table 1). In bud wood nurseries significant level of disease control was achieved with fungicide application during the immature period. $90.94 \%$ leaves were infected in the control while the treated plants had only $23.5 \%$ (Table 2). The results from the field plants also showed a similar pattern. The average infected leaves in the treated field plants was $3.32 \%$ while the control twigs showed an average of $72.28 \%$ (Table 2). The incidence of the disease in the field experiments was high and this is probably due to the failures of the action of the fungicide. According to the observations the difference is apparent between the two treatments and Fig. 1 shows the statistical analysis of the field data.

Based on the results, it is very clear that the establishment of the Corynespora cassiicola in CLFD susceptible clones occur mainly at the time of refoliation. The newly emerging tender leaves in the presence of favourable climatic conditions appear to be highly susceptible to the disease. As a result of infection, defoliation occurs and often, newly emerging leaves are also attacked by the pathogen leading to repeated defoliation. As a results the disease prevails on the plant throughout the year. Hence, when chemical control programmes or any other cultural practices are employed for the management of CLFD, the control measures should be mainly applied during the period of refoliation. Approximately $85 \%$ of the leaves which were chemically protected at the time of refoliation remained healthy up to the end of the year. The number of fungicide sprays could thus be reduced by confining the sprays to the refoliation period. This observation would be very useful in preparing fungicide application schedules which would be important in rehabilitating CLFD affected clearings in sudden outbreaks.

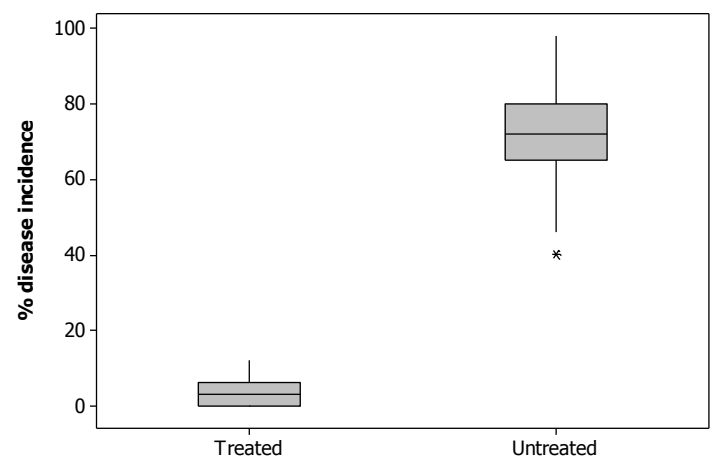

Fig. 1. Box plot to show the data distribution between the two treatments. Treated - Protected with fungicides, Untreated - control (without fungicide application) 


\section{Acknowledgement}

Authors wish to thank $\mathrm{Mr}$ Keminda Herath for statistical analysis and Miss Madushani for word processing.

\section{References}

Brown, A E and Soepena, H (1994). Pathogenicity of Colletotrichum acutatum and C. gloeosporioides on Hevea spp. Mycological Research 98, 264-266.

Dung, P T and Hoan, N T (1999). Corynespora Leaf Fall on rubber in Vietnam new record. Proceedings of IRRDB Symposium, 1999, Hainan, Peoples' Republic of China. (Eds. Chen Quibo and Zhou Jiannan), Hainan Publishing House, China, pp. 273-275.

Jacob, C K (2003). Disease of potential threat to rubber in India. Planters' Chronicle 92 (10), 451-461.

Jayasinghe, C K (2000). Corynespora Leaf Fall of rubber in Sri Lanka: Diversity of the pathogen and pathogenesis. IRRDB Workshop on Corynespora Leaf Fall of Rubber, 6-9 June 2000, Kuala Lumpur, Malaysia.

Jayasinghe, C K, Silva, W P K and Wettasinghe, D S (1999). Corynespora cassiicola: A fungal pathogen with diverse symptoms on Hevea rubber. Bulletin of the Rubber Research Institute of Sri Lanka 39, 1-5.

Jini, P, Zhang, X, QiY, Xie Y, Zhang, H, and Zang, $H$ (2007). First record of Corynespora leaf fall disease of Hevea rubber tree in China. Australasian Plant Disease Notes 2, 35-36, doi:10

Kajornchaiakul, P (1987). Corynespora disease of Hevea in Thailand. Proceeding of IRRDB Symposium on Pathology of Hevea brasiliensis, 2-3 November 1987, Chang Hai, Thailand, pp. 1-5.

Liyanage, A de $\mathrm{S}$, Jayasinghe, $\mathrm{C} \mathrm{K}$, Liyanage, N I S and Jayarathna, A H R (1986). Corynespora leaf spot disease of rubber (Hevea brasiliensis). A new record. Journal of Rubber Research Institute of Sri Lanka $\mathbf{6 5}, 47-50$.

Newsam, A (1961). Rubber Research Institute of Malaysia Pathology, Division Report, 1960: 63-70.

Pongthep, K (1987). Corynespora disease of Hevea in Thailand. IRRDB's Symposium on pathology of Hevea in Chieng Mai, Thailand.

Ramakrishnan, $\mathrm{T} \mathrm{S}$ and Pillay, $\mathrm{P} \mathrm{N} \mathrm{R}$ (1961). Leaf spot of rubber caused by Corynespora cassiicola (Berk. \& Curt.) Wei. Rubber Board Bulletin 5, 52-53.

Soepena, H (1985). Corynespora: The causal agent of leaf fall in rubber plants (Indonesia). Warta Perkaretan 4 (2), 1314.

Address for correspondence: Mrs T.H.P.S. Fernando, Assistant Plant Pathologist, Rubber Research Institute of Sri Lanka, Dartonfield, Agalawatta, Sri Lanka. E-mail: thpsfernando@yahoo.com 